\title{
Inhaling and lung cancer: an anomaly explained
}

\author{
NICHOLAS J WALD, MARIANNE IDLE, JILLIAN BOREHAM, ALAN BAILEY
}

\begin{abstract}
An objective index of inhaling cigarette smoke based on carboxyhaemoglobin concentrations and the carbon monoxide yields of cigarettes was used to investigate possible systematic differences in the extent of inhaling among light and heavy smokers when classified according to their self described inhaling habits. A total of 2108 men who smoked cigarettes were studied. Heavy smokers (20 or more cigarettes a day) had a higher average inhaling index than light smokers (fewer than 20 cigarettes a day) both among those who said that they inhaled and among those who said that they did not. This observation, together with indirect evidence that heavy smokers who inhale deeply may to some extent avoid depositing smoke condensate on their main bronchial epithelium, explains a hitherto unresolved anomaly-namely, that the risk of lung cancer is less among heavy cigarette smokers who say that they inhale than it is among those who say that they do not inhale.
\end{abstract}

ICRF Cancer Epidemiology and Clinical Trials Unit, Radcliffe Infirmary, Oxford OX2 6HE

NICHOLAS J WALD, MB, MRCP, deputy director

MARIANNE IDLE, BSC, research assistant

JILLIAN BOREHAM, PHD, computer programmer

BUPA Medical Research, London WC1X 8DU

ALAN BAILEY, MB, MRCP, director

Correspondence to: Professor Nicholas J Wald, Department of Environmental and Preventive Medicine, St Bartholomew's Hospital Medical College, Charterhouse Square, London EC1M 6BQ.

\section{Introduction}

There is an anomaly in the relation between self described inhaling of tobacco smoke and lung cancer: heavy smokers who say that they inhale develop less lung cancer than those who say that they do not inhale. Table I summarises the results from three retrospective studies of patients with lung cancer and controls without lung cancer ${ }^{1}$; all three yielded similar results. The first, by Doll and Hill, showed little difference in the proportion of self described inhalers among patients and controls who smoked fewer than 15 cigarettes daily. Among smokers of 15 or more cigarettes a day the proportion of inhalers among patients with lung cancer was less than it was among controls. In the second retrospective study, Schwartz and colleagues found a greater proportion of inhalers among patients with lung cancer who smoked fewer than 30 cigarettes a day, although the excess of inhalers among patients with lung cancer diminished with increasing smoking, and was reversed among subjects with the greatest cigarette consumption. Similar results were obtained by Spicer in the third retrospective study.

TABLE I-Proportions of subjects in three studies* who reported that they inhaled tobacco smoke among patients with lung cancer and control patients by cigarette consumption. (From Wald and Doll ${ }^{1}$ : summary of data from the three studies)

\begin{tabular}{|c|c|c|c|c|c|c|}
\hline \multirow{3}{*}{$\begin{array}{l}\text { No of } \\
\text { cigarettes/ } \\
\text { day }\end{array}$} & \multicolumn{6}{|c|}{ Reported inhalers (\%) } \\
\hline & \multicolumn{2}{|c|}{ Doll and Hill } & \multicolumn{2}{|c|}{ Schwartz et al } & \multicolumn{2}{|c|}{ Spicer } \\
\hline & $\begin{array}{l}\text { Patients } \\
\text { with lung } \\
\text { cancer }\end{array}$ & $\begin{array}{l}\text { Control } \\
\text { patients }\end{array}$ & $\begin{array}{l}\text { Patients } \\
\text { with lung } \\
\text { cancer }\end{array}$ & $\begin{array}{l}\text { Control } \\
\text { patients }\end{array}$ & $\begin{array}{c}\text { Patients } \\
\text { with lung } \\
\text { cancer }\end{array}$ & $\begin{array}{l}\text { Control } \\
\text { patients }\end{array}$ \\
\hline $1-4$ & 50 & 48 & & & & \\
\hline $\left.\begin{array}{c}5-9 \\
10-14\end{array}\right\}$ & 81 & 79 & $\zeta 50$ & 29 & $\left\{\begin{array}{l}58 \\
79\end{array}\right.$ & $\begin{array}{l}38 \\
81\end{array}$ \\
\hline $\left.\begin{array}{l}15-19 \\
20-24\end{array}\right\}$ & 72 & 82 & 559 & 46 & 75 & 83 \\
\hline $\left.\begin{array}{r}25-29 \\
\geqslant 30\end{array}\right\}$ & 62 & 71 & 60 & 72 & 68 & 81 \\
\hline
\end{tabular}

"References given by Wald and Doll." 
Two prospective studies yielded the same conclusion. Doll and Peto reported that among light (1-14 cigarettes a day) and moderate (15-24 cigarettes a day) smokers the mortality rates from lung cancer were, respectively, 1.81 and 1.51 times higher in men who said that they inhaled than in men who said that they did not. ${ }^{2}$ For men who smoked 25 or more cigarettes a day, however, the rate among "inhalers" was 0.56 of that among "non-inhalers." More recently Higenbottam et al obtained similar results in the Whitehall study. ${ }^{3}$ Among light smokers (1-9 cigarettes a day) the mortality rate was 1.16 times higher in self reported inhalers than in non-inhalers, among moderate smokers (10-19 cigarettes a day) the rates were similar, and among heavy smokers ( 20 or more cigarettes a day) the rate was only 0.70 of that in inhalers.

All these studies were therefore consistent in showing that, as cigarette consumption increases the risk of lung cancer among self reported inhalers compared with self reported non-inhalers changes from being greater than one to being less than one.

We describe a model to explain the anomaly between lung cancer and inhaling and present data to test the model.

\section{The model}

Self described inhaling habits are an imprecise measure of the extent to which cigarette smoke is actually inhaled into the lungs. For example, many smokers who say that they do not inhale in fact inhale enough cigarette smoke to raise their carboxyhaemoglobin concentrations well above those in non-smokers. ${ }^{4}$ Apart from such random variation in self described inhaling habits, however, there are likely to be systematic differences in inhaling between heavy and light smokers. It would be surprising if heavy smokers (who are perhaps more dependent on smoking) did not inhale on average to a greater extent than light smokers. Certainly the proportion of self described inhalers is higher among heavy smokers than among light smokers. In addition, but not hitherto explored, is the possibility that even among self described non-inhalers heavy smokers may on average inhale more than light smokers who also say that they do not inhale. Similarly, among self described inhalers heavy smokers may inhale more than light smokers.

The figure shows these patterns of inhaling schematically. The left half of the figure compares the presumed extent of inhaling of a light smoker who says that he does not inhale (A) with that of a light smoker who says that he does (B). On average, A takes little of the smoke taken into his mouth beyond the larynx, while $B$ transfers the smoke further along the respiratory tract so that much of it reaches the main bronchi. The right half of the figure illustrates the presumed extent of inhaling in a heavy smoker (A) who says that he does not inhale compared with that in a heavy smoker $(B)$ who says that he does. A deposits much of the smoke taken in through the mouth as far into his lungs as the main bronchi, but B transfers much of the smoke further, into the peripheral parts of the lungs.

According to this model, if allowance is made for total amount smoked, and bearing in mind that the principal target site for lung cancer is the epithelium of the main bronchi, we should expect that among light smokers the inhaler (B) would have a higher risk of lung cancer than the non-inhaler (A), but that among heavy smokers the non-inhaler (A) would have a higher risk of lung cancer than the inhaler (B).

Such a model therefore rests on two hypotheses: (a) that self described inhaling in fact reflects a systematically different extent of inhaling among light and heavy smokers, and $(b)$ that smokers who inhale deeply can avoid depositing much of the smoke condensate on their main bronchi and thereby unwittingly protect themselves against the risk of developing tumours at this site. Taken together these two hypotheses explain satisfactorily why among light smokers self described inhalers have a higher risk of lung cancer than self described non-inhalers, whereas among heavy smokers the converse applies.

In this study we used a previously described ${ }^{5}$ objective index of inhaling based on carboxyhaemoglobin concentrations and the carbon monoxide yields of cigarettes smoked to investigate whether there are indeed systematic differences in the extent of inhaling among light and heavy smokers according to their self described inhaling habits.
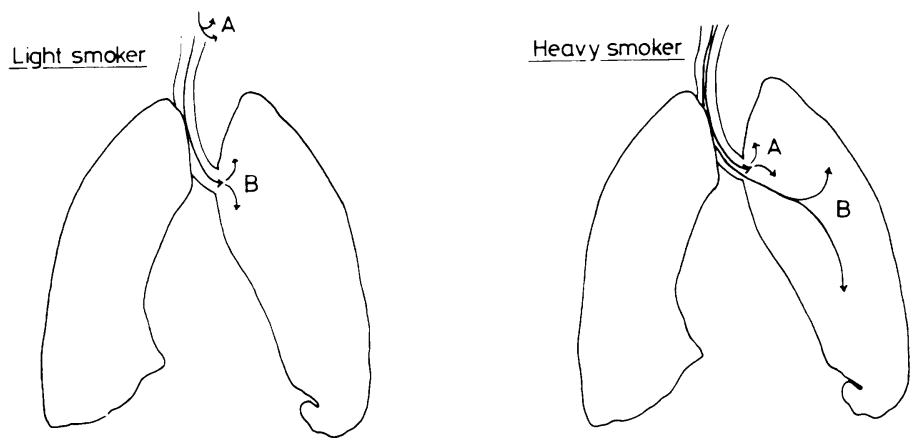

Possible inhaling pattern of self described non-inhaler (A) and self described inhaler (B) according to cigarette consumption. Arrows indicate main site of tobacco smoke deposition in respiratory tract that might occur in each of the four examples. (Light smoker $<20$ and heavy smoker $\geqslant 20$ cigarettes/day).

\section{Methods}

The study population was as described. ${ }^{5}$ In brief, the subjects were male cigarette smokers aged 35-64 years who attended the BUPA Medical Centre in London for comprehensive health screening. Detailed information was obtained on smoking habits, and each man was asked to what extent he usually inhaled tobacco smoke. For this analysis the men were categorised into those who said that they did not inhale and those who said that they did. Blood was also taken for estimation of carboxyhaemoglobin concentration, and the yields of carbon monoxide of the brands of cigarettes smoked were obtained from the Tobacco Advisory Council. The carboxyhaemoglobin inhaling index for each person was calculated by dividing the excess carboxyhaemoglobin (measured carboxyhaemoglobin concentration minus an estimated contribution from the carryover from the previous day's smoking and minus the estimated background concentration from endogenous and atmospheric carbon monoxide) by the carbon monoxide yield of the brand of cigarettes smoked, and then standardising for the number of cigarettes (in single cigarette groups $1,2,3$, etc) smoked on the day of the test before blood was taken, as described. ${ }^{5}$

\section{Results}

Table II shows the carboxyhaemoglobin inhaling index (multiplied by 100 ) among light smokers (who usually smoked fewer than 20 cigarettes a day) and among heavy smokers (who usually smoked 20 or more cigarettes a day) classified according to whether or not they said that they inhaled the smoke. Heavy smokers who said that they did not inhale had a higher average inhaling index than the light smokers who said that they did not inhale (19 $v$ 14), although the

TABLE II-Standardised inhaling index and mean time of blood test according to cigarette consumption and inhaling habits. (Standardised inhaling index expressed as percentage of carboxyhaemoglobin per mg carbon monoxide: $\% \mathrm{COHb} / \mathrm{mg} \mathrm{CO}$ )

\begin{tabular}{|c|c|c|c|c|c|c|}
\hline \multirow{2}{*}{$\begin{array}{l}\text { Self reported } \\
\text { inhaling } \\
\text { category }\end{array}$} & \multicolumn{3}{|c|}{ Light smokers ( $<20$ cigarettes/day) } & \multicolumn{3}{|c|}{ Heavy smokers ( $\geqslant 20$ cigarettes/day) } \\
\hline & No of men & $\begin{array}{c}\text { Standardised } \\
\text { inhaling index } \\
(\% \mathrm{COHb} / \mathrm{mg} \mathrm{CO})\end{array}$ & $\begin{array}{l}\text { Mean time } \\
\text { of blood test } \\
\text { (hours) }\end{array}$ & No of men & $\begin{array}{c}\text { Standardised }{ }^{*} \\
\text { inhaling index } \\
\left(0_{\mathrm{O}} \mathrm{COHb} / \mathrm{mg} \mathrm{CO}\right)\end{array}$ & $\begin{array}{c}\text { Mean time } \\
\text { of blood test } \\
\text { (hours) }\end{array}$ \\
\hline $\begin{array}{l}\text { Non-inhaler } \\
\text { Inhaler }\end{array}$ & $\begin{array}{r}42 \\
632\end{array}$ & $\begin{array}{l}14 \\
19\end{array}$ & $\begin{array}{l}1448 \\
1448\end{array}$ & $\begin{array}{r}57 \\
1377\end{array}$ & $\begin{array}{l}19 \\
22+\end{array}$ & $\begin{array}{l}1430 \\
1436\end{array}$ \\
\hline
\end{tabular}

* Standardised for number of cigarettes smoked before blood test.

+Statistically significantly greater than light smokers saving that thev inhaled ( $<<0.05$; randomisation test). 
difference was not statistically significant. Similarly, heavy smokers who said that they did inhale had a statistically significantly higher average inhaling index than light smokers who said that they did inhale $(22 v 19 ; \mathrm{p}<0.05)$. Interestingly, the inhaling index for light smokers who said that they did inhale was identical with that of the heavy smokers who said that they did not.

\section{Discussion}

Our results on inhaling support the first of the two hypotheses specified above-namely, that self described inhaling reflects a systematically different extent of inhaling among light and heavy smokers.

Since carbon monoxide is absorbed through the lungs and combines with haemoglobin to form carboxyhaemoglobin, and absorption of carbon monoxide through the mouth or pharynx does not appear to occur, we are reasonably confident that our carboxyhaemoglobin inhaling index is a reliable measure of inhaling smoke to the peripheral pulmonary alveoli. Nevertheless, while the rise in carboxyhaemoglobin due to smoking is affected by the extent to which cigarette smoke is inhaled, it is also affected by various other factors including the number and type of cigarettes smoked and the pattern of smoking. In using carboxyhaemoglobin concentrations as an index of inhaling it is necessary to allow for these factors, and our previous paper ${ }^{5}$ explains in detail how we did this.

Certain problems may have arisen in our present study. Systematic differences in the pattern of smoking cigarettes during the day among heavy and light smokers might have accounted for differences in their concentrations. For example, although we allowed for the number of cigarettes before the test in our inhaling index, heavy smokers are likely to smoke a given number of cigarettes in a shorter period than light smokers-in other words, blood might have been taken from our heavy smokers earlier in the day. As a result they would have had less time to eliminate carbon monoxide from their bodies and so would have had higher carboxyhaemoglobin concentrations even if they inhaled to the same extent as light smokers. Since the purpose of this study was to use carboxyhaemoglobin concentrations as a measure of inhaling, it was important to avoid this bias; hence the analysis shown in table II was restricted to men who had blood taken at about the same time of day between 1300 and 1600 hours. The average time when blood was taken was, in fact, closely similar for heavy and light smokers regardless of whether they said that they inhaled (light smokers 1448 hours for both non-inhalers and inhalers; heavy smokers 1430 and 1436 for non-inhalers and inhalers respectively).

A further check was also carried out to see if the special conditions on the day of the test might have affected the smoking habits of heavy smokers as compared with light smokers. For each of the two categories of smokers (heavy and light) the number of cigarettes smoked before the test was expressed as a proportion of the total number they would have smoked on a typical day by that time. The average proportions were similar (light smokers $97^{\circ} \circ$ and $92^{\circ}$ ' , for non-inhalers and inhalers respectively, heavy smokers $84^{\circ} \circ$ and $82^{\circ} \circ$ respectively), suggesting that this was not a problem.

Other factors that affect carboxyhaemoglobin concentrations, such as alveolar ventilation, were unlikely to account for the differences in concentrations between our heavy and light smokers or between the self reported inhalers and non-inhalers, because their average level of physical activity was similar. The average reported time spent sitting each day was eight hours for each group, and the maximum difference in reported vigorous exercise between the groups was only nine minutes a day. It does seem therefore that our results on inhaling were real and not due to bias.

The carboxyhaemoglobin inhaling index reflects the combination of three components of inhaling: number of puffs, puff volume, and depth to which the smoke is inspired into the lungs. In this paper our argument relates to the third component, the inspiratory phase of inhaling. This component is probably the main determinant of the inhaling index, since the variation in puff volume and number of puffs per cigarette among smokers smoking cigarettes of different tar and nicotine yields is less than it is for the inhaling index itself. ${ }^{6}$

We did not investigate directly the second of the two hypotheses specified above-namely, that smokers who inhale deeply avoid depositing much of the smoke condensate in their main bronchi and thereby protect themselves against developing tumours at this site. This view is not new ${ }^{2}$ and is biologically plausible. Direct evidence which addresses the question is available from the study of smoking and lung cancer described by Doll and Hill in 1952. "They found that a higher proportion of smokers with peripheral lung cancers said that they inhaled compared with smokers having central tumours $(63 \%$ v $52 \%$; $\mathrm{p}<0.005)$, although there was no statistically significant difference in the cigarette consumption. The relation between inhaling and the incidence of lung cancer is of course probably more complex than the simple model referred to here, being dependent on physical characteristics of the smoke (such as particle size) as well as on its chemical characteristics. Nevertheless, the only piece of evidence that we can find on the question apparently supports the hypothesis.

Interestingly the inversion of risk of lung cancer (the relative risk changing from greater than one to less than one) among self described inhalers and non-inhalers which occurs as the amount smoked increases is not apparent with another condition associated with smoking, coronary heart disease. ${ }^{4}$ The risk of that disease is higher among self described inhalers than non-inhalers at all levels of cigarette consumption. This is not surprising, since the constituent of smoke responsible for coronary heart disease is thought to be absorbed through the peripheral alveoli rather than deposited on the central bronchi, and therefore no inversion in risk would be expected.

In summary, therefore, we have evidence from our own study supporting the first hypothesis and evidence from a previous study supporting the second. Together they explain why heavy smokers who say that they inhale develop less lung cancer than those who say that they do not inhale. This apparent anomaly has been interpreted by some as suggesting that smoking was not a cause of lung cancer but was merely associated with the disease through sharing a common cause, such as a particular genetic constitution. Sir Ronald Fisher, in particular, took this view, ${ }^{8}$ and much of his argument that smoking was not a cause of lung cancer was based on this apparent anomaly. The explanation for this anomaly invalidates such arguments.

We thank Sir Richard Doll, Professor G Rose, Dr L J Kinlen, and Dr H S Cuckle for their comments, the Tobacco Advisory Council for providing the carbon monoxide yields of the different brands of cigarette, and the Medical Research Council for contributing to our financial support.

\section{References}

1 Wald NJ, Doll. R Epidemiology of lung cancer. In: Wynder EL, Hecht S, eds. Lung cancer. Geneva: UICC, 1976. (UICC Technical Report Series. Vol 25. Report No 3.)

2 Doll R, Peto R. Mortality in relation to smoking: 20 years' observations on male British doctors. Br Med f 1976;ii:1525-36.

${ }^{3}$ Higenbottam T, Shipley MJ, Rose G. Cigarettes, lung cancer, and coronary heart disease: the effects of inhalation and tar yield. Fournal of Epidemiology and Community Health 1982;36:113-7.

- Wald NJ, Idle M, Bailey A. Carboxyhaemoglobin levels and inhaling habits in cigarette smokers. Thorax 1978;33:201-6.

${ }^{5}$ Wald NJ, Idle M, Boreham J, Bailey A. Smoking habits among smokers of different types of cigarette. Thorax 1980;35:925-8.

${ }^{6}$ Adams PI. The influence of cigarette smoke yiclds on smoking habits. In: Thornton RE, ed. Smoking behaviour: physiological and psychological influences. Edinburgh: Churchill Livingstone, 1978:349-60.

${ }^{7}$ Doll R, Hill AB. The study of the aetiology of carcinoma of the lung. Br Med f 1952; ii:1271-86.

${ }^{8}$ Fisher RA. Smoking: the cancer controversy. Edinburgh and London: Oliver and Boyd, 1959.

(Accepted 2 August 1983) 